\title{
How a Successful Idea Traveled: Implementing the Engineering Teaching Portfolio Program at University of Florida
}

\author{
Raluca I. Rosca, Diane P. Hickey \\ Mechanical and Aerospace Engineering Department, University of Florida/ \\ Material Science Engineering, University of Florida
}

\begin{abstract}
The paper describes the successful implementation at the University of Florida of the Engineering Teaching Portfolio Program, first developed at University of Washington, Seattle. The local version of the program (ETP-UF) was realized as a graduate student program of the Society of Women Engineers, Gainesville Student branch and supported by the Dean of Graduate Studies in the College of Engineering. The first offering of ETP-UF took place during the last half of the Fall 2004 semester, and a second offering is advertised for Spring 2005.
\end{abstract}

\section{Introduction}

The general objectives of the Engineering Teaching Portfolio Program (ETP), as well as the outcomes of the first offering were presented at the 2004 ASEE Annual Conference ${ }^{1}$ by its designers at the NSF-funded Center for Advancement of Engineering Education at University of Washington. In short the program strives to better prepare graduate students in engineering for the teaching component of an academic career, by offering an eight week, step-by-step approach to writing a teaching statement and researching for supporting evidence, as well as by creating a network of peers and facilitating reflection upon teaching styles and methods. The first author of this paper had seen the presentation and was interested in the seeing the program happen at her home institution, University of Florida (UF), if not in an organized manner than at least in a social get-together form.

University of Florida has an active Teaching Center that coordinates tutoring activities and provides professional development for all graduate students teaching assistants on its 48000 students campus, as well as a University Center for Excellence in Teaching that supports professional development of post-doctoral associates and faculty. Those two centers were developed from similar centers serving the College of Liberal Arts and Sciences, and as such they are not very well known to the engineering graduate students and faculty. Moreover, with the focus of UF being research, and teaching assistantships being seen as second rate to research assistantships, there is no critical mass of graduate students in any given engineering department interested in teaching development. However, the author assumed that at the level of College of Engineering this critical mass can be created, and furthermore, engineering students will respond better to a program organized by engineers for engineers than to a university-wide initiative.

"Proceedings of the 2005 American Society for Engineering Education Annual Conference and Exposition Copyright (C) 2005, American Society for Engineering Education", 
A good house for such a program would be the graduate student section of any professional engineering society. With most student branches of engineering societies having very active undergraduate student participations, and small to nonexistent graduate student constituency, this type of program can be seen by the engineering society as a tool to increase its graduate student membership and participation of the graduate students in the given society. While a student branch of ASEE would be a logical place to host such an initiative, there is no such a branch on UF campus, so an alternative was considered.

Because the author was mostly active in the local branch of Society of Women Engineers (SWEUF), she approached the Gainesville student branch officers with a hosting offer for ETTP-UF. The second author, the SWE-UF graduate student coordinator, was very receptive to this idea, and SWE-UF offered logistic support in arranging for meeting space, offering chips and refreshments and advertising the program to its members. Moreover, Dr. Andersen, the Associate Dean for Research and Graduate Programs in College of Engineering endorsed the idea and helped advertising it through its official email list. From the first discussion about the program until the first meeting less than five weeks passed.

\section{Advertising and Recruiting}

The program was advertised using four previously existent email lists: (1) the SWE-UF members list, (2) the engineering graduate student email list, (3) the engineering faculty and (4) the engineering department graduate coordinators. There is no similar email list at the level of College of Engineering grouping the post-doctoral associates, so we relied on the engineering faculty to inform their post-doctoral associates about the program.

The text of the email submitted directly to the graduate students is shown in Fig. 1 while the emails sent to the engineering faculty and department coordinators contained the same text, preceded by the invitation to refer their interested students and post-doctoral associates to this program. The SWE-UF members (mostly undergraduates) had received a shorter email announcing the program.

The initial answer to these emails was very encouraging, with 35 students and six post-doctoral associates expressing interest in the program or requiring further information. Classified by the department they identified themselves as belonging to, we had 12 participants from Electrical Engineering, four from Mechanical and Aerospace Engineering, three from Agricultural Engineering, two each from Civil Engineering and Materials Science, one each from Biomedical Engineering, Computer and Information Science, and Environmental Engineering, and nine unidentified ones.

While apparently excessive (ideally, any graduate student would have received the same email three times - once directly and twice forwarded from their advisor and graduate student coordinator), the email bombardment proved to be barely sufficient, with one engineering graduate student reporting not receiving any email on the subject. The respondents from Electrical Engineering were quoting an email from their department graduate coordinator as the source of their information, while various other respondents quoted either direct email or recommendation from their advisors as the source of information.

"Proceedings of the 2005 American Society for Engineering Education Annual Conference and Exposition Copyright (C) 2005, American Society for Engineering Education" 
Figure 1: Text of the 10/10/2004 email send to the engineering graduate students list to advertise the ETP program

Thinking about, looking for or about to start searching for an Academic Position? Do you have your TEACHING PORTFOLIO ready yet?

If you are a graduate student or post-doc about to start or already on the search for an Academic Position, this workshop series is for you! Email Raluca Rosca (rarosca@ufl.edu) by October15th to reserve your seat.

The SWE is sponsoring an 8-session workshop series that will provide you with more KEYS TO SUCCESS in your academic job hunt. At the end of the 8 weeks (about $1.5 \mathrm{hrs}$ per session), you will have:

- The ability to articulate your teaching experience

- A complete TEACHING PORTFOLIO to present during your interviews, including:

o your own 'Teaching Philosophy' statement

o 2-3 annotated 'artifacts' (Syllabi, Tests and Homework that you have prepared or used as a TA)

o a diversity statement

- $\quad$ The opportunity to interact with colleagues interested in a faculty career.

This is not a seminar series or an information session, but an engineeringfocused, peer-conducted TEAM ACTIVITY. We will use the materials developed by the NSF - Center for the Advancement of Engineering Education and already tried at the University of Washington (http://www.engr.washington.edu/caee/ETPP_site/)

YOU will work on your own teaching philosophy statements (and offer constructive criticism for everybody's else), find teaching artifacts to support your statements (and offer suggestions/criticisms for how somebody's else given artifact does support an idea in their teaching statement), and basically get on thinking about why do you want to go in academe and what would it take to be successful 'out there'. On short, you will be BETTER PREPARED FOR YOUR ACADEMIC JOB SEARCH.

Fall sessions begin Monday October 18th.

Email Raluca Rosca (rarosca@ufl.edu) by October15th to participate.

A second email was addressed to the respondents of the first email, to announce the first meeting of the program, answer the specific questions of the respondents, and clarify the fact that ETP does not constitute an academic job search program, but rather a program to improve the part of an academic job application describing the candidate's experience and interest in teaching.

"Proceedings of the 2005 American Society for Engineering Education Annual Conference and Exposition Copyright (C) 2005, American Society for Engineering Education", 
As a result, 20 students had attended the first meeting of the program, and subsequently decided to break into 3 smaller groups, two groups of 8 people each meeting at the same time on Monday in two different locations on campus and one group of four people meeting on Tuesday. Four students have announced via email that they have interest in the program, but time conflicts for this semester and plan to participate in it in the future. Two other interested parties were offcampus students, so they were referred to the web-resources available on the University of Washington web-site.

While the number of the respondents (20) may feel very small, it is comparable in size with the number of 2004-2005 possible Ph.D. graduate students that take a first job in academia. Indeed, University of Florida graduated $127 \mathrm{Ph} . \mathrm{D}$. in $2003^{2}$ and historically about $15 \%$ of its $\mathrm{Ph} . \mathrm{D}$. graduates take their first job in academia, so assuming the graduation numbers for 2004-2005 to be comparable with the ones for 2003-2004, the target audience for the ETP program would be 19 students. The authors were not able to find data about the number of post-doctoral associates presently working in College of Engineering or the percentage of those who are interested in an academic career.

\section{Tangible and intangible results}

From the 20 people initially registered in the three groups, 4 completed a second review of the Teaching Philosophy statement (four out of the eight sessions). Three of those identified also a teaching artifact for their portfolio and two of them had completed by the end of the program a teaching portfolio including a thoroughly reviewed teaching philosophy statement and at least two teaching artifacts. The two participants who completed the program were in the process of applying for academic positions and announced to the group that they started to submit the portfolio with their job applications. In an affectionate manner, the group proclaimed them 'the star finalists'.

\section{Discussion}

The tangible results of the first implementation are not as impressive as expected by the authors, the intangible effects however are much larger. Most of the students who left the program did that after the first three meetings/ after a time investment of 3-4.5 hours. By that time they were exposed, many for the first time, to a discussion about the Carnegie Foundation classification of the higher education institution and to the different ration of teaching and research at different institutions. They have talked about the idea of an engineering teaching portfolio, have analyzed engineering teaching portfolios available on-line and in most cases accepted enthusiastically the idea of a developmental teaching portfolio, a documented archive of their teaching activities, of any teaching materials that they have developed and also of any official or alternative feedback regarding teaching from their supervisors and their students.

At this point, many participants had decided that because their experience as teaching assistants reduces only to grading papers, they do not have enough data to develop a teaching portfolio right now. Some of those participants decided to leave the program all together, complete the program one year later, and in the mean time to enlarge their teaching experience by using the strategies discussed in the meeting, proactively looking for teaching in formal or informal

"Proceedings of the 2005 American Society for Engineering Education Annual Conference and Exposition Copyright (O) 2005, American Society for Engineering Education” 
settings. Other participants decided they can not complete the program per se, but would like to 'audit' as many of the following discussions as possible.

Without exception, all participants appreciated the opportunity to discuss their own teaching experiences and career goals, hear about other students' experiences, and learn in a nonthreatening, non-competitive environment, useful strategies for success in an academic career. While they greatly appreciated the program materials graciously provided by the University of Washington researchers, they recognized that if not for the program, they would not have made the effort to read those materials, or take the time to complete any of the writing exercises (write a teaching philosophy statement and look for artifacts to support it, think about the diversity statements). Even those who didn't write any of those statements felt that by participation in the program they have accumulated information and strategies for future success. The intangible results of the first offering greatly surpassed the tangible ones.

Among the most fruitful discussion was the one centered on the diversity statements. All but two of the participants were not aware of the 'broader impact' criteria in the NSF proposals and the subsequent diversity requirement. At the start of the discussion, the participants defined diversity in terms of race and sex, and thought of it as a politically sensitive issue upon which a job applicant better doesn't comment, while by the end of the discussion diversity was also defined in terms of age and life experiences, and the whole issue proved to be at least worth thinking about.

In the first author's opinion, given that the new engineering faculty is among the least prepared to teach from all the other faculty on campus, and their students in the first two year of practice are the most likely to suffer from this lack of pedagogical and human interaction experience, any program that prepares a graduating Ph.D. or a post-doctoral associate for a real teaching experience is an useful program and an extra help that an institution can provide for the success of its graduates and associates. We were encouraged to see the same attitude expressed at the level of the Associate Dean for Research and Graduate Programs, a Chemical Engineering professor that was also one of the organizers of SUCCEED on UF campus.

\section{Recognized Issues of Our Implementation and Suggested Improvements}

In retrospective, a number of problems in our implementation could have been prevented. We are listing them in here, together with the implementation modifications for the second offering of ETP-UF (Spring 2004), in the hope that anybody else interested in implementing the program on their campus can benefit from our hard-won wisdom.

In the informal discussion with both the participants that graduated from ETP and the ones that left the program mid-way, the issue of time management was mentioned. While the participants described that they have not spent more than 3 hours a week (1 1/2 in class and 1 1/2 outside class) to prepare for this program, finding this time was a problem, especially so because the program took place in the last half of the fall semester, with midterms, finals and Thanksgiving interfering. As a result, the offering for the Spring semester is scheduled to start in the third week of school, and end just after Spring Break. Another suggested modification is to schedule the ETP meetings in the week preceding the school start, in a workshop-type format. While this

"Proceedings of the 2005 American Society for Engineering Education Annual Conference and Exposition Copyright (C) 2005, American Society for Engineering Education"” 
approach might have the efficiency advantage, the first author can see the logistics disadvantages as well as a loss in the reflection time (in other words, what might be gained in the quantity of the product might be lost in the quality of the production process). Others may disagree with this opinion and advocate even for a more concentrated approach, for example a week-end workshop.

Another problem mentioned by participants was the fluctuating number of participants from a session to the next and the unequal preparation for the weekly ETP meeting of different participants. This was also related to the crunch time experienced by participants due to outside deadlines. The modification suggested for the second offering was to keep all the initial participants in the same group (as big as 20 people) with the understanding that the number of participants would decrease later in the program. In our program, we observed that a minimum of 4 participants in a meeting, at least two of them well prepared, guaranteed a useful and lively discussion, while anything less than that made for a slower discussion and a decreased perceived usefulness.

Yet another problem is the presence of an 'official facilitator' in the group. Out of the three initial groups, the one that kept meeting until the end was the one where an 'official facilitator' (i.e. the first author) was identified. All three groups started with the same premise of giving every member in the group the chance to facilitate, at least partially, a meeting; however after fact most participants expressed increased confidence in their abilities of facilitating a meeting if they knew that somebody else can take over if they falter. We have to stress that this is a question of perceived ability as opposed to true ability. In our next implementation, the 'star finalists' of the Fall offering will play the 'official facilitator' for the Spring offering.

\section{Future Plans}

As mentioned in a number of places above, the next offering of the ETP-UF program is scheduled for Spring Semester 2005. After that, SWE-UF plans to continue offering the program on an annual basis, at the beginning of fall semester. After a first offering of the program on a campus, there is little maintenance work needed to keep reorganizing the program. We have seen in our offering that successful graduates of ETP express the will to help reorganizing this program, so ETP has indeed the potential to become a self-sufficient program. Presently we have filed a protocol with the Institutional Review Board to collect data on both offerings of ETP.

We are also happy to report that this first offering started a discussion between the office of Dean of Engineering, SWE-UF, the Career Resource Center and other entities on campus about the necessity and the possibility of organizing a multi-year integrated program of activities to supplement the academic preparation of graduate students with a preparation for the job market. We hope to be able to report by the next conference about the progress of these discussions.

\section{Acknowledgements}

The authors gratefully acknowledge the moral support and encouragement of Dr. Tim Andersen, the Associate Dean for Research and Graduate Programs in UF College of Engineering, as well as the multiplication of program materials cost supported by Benton Engineering Council/ SWE-

"Proceedings of the 2005 American Society for Engineering Education Annual Conference and Exposition Copyright (C) 2005, American Society for Engineering Education” 
UF. The first author wants to thank Jessica Yellin and Jennifer Turns at Center for the Advancement of Engineering Education (CAEE), University of Washington for the useful discussions at the 2004 ASEE Conference and all throughout the Fall 2004 semester. The National Science Foundation had funded through CAEE grant ESI-0227558 the initial development of the ETP materials at University of Washington and their subsequent modifications which we have used at UF. Last but not least, great many thanks are due to the participants in the ETP-UF program.

\section{References}

1. Linse, Angela, Jennifer Turns, Jessica M.H. Yellin, and Tammy VanDeGrift (2004). Preparing Future Engineering Faculty: Initial Outcomes of an Innovative Teaching Portfolio Program. Proceedings of the 2004 ASEE Annual Conference and Exposition. Salt Lake City, UT. Document 1416

2. University of Florida College of Engineering Annual Report 2004

$<$ http://www.eng.ufl.edu/home/pubs/annualreports/tponi.pdf $>$;URL accuracy confirmed on January 4, 2005

\section{Biographical Information}

Dr. RALUCA IOANA ROSCA is a Post-Doctoral Associate in the Mechanical and Aerospace Engineering Dept. at University of Florida (UF) and holds a Ph.D. in Engineering Mechanics from UF. Her research interests are in applied mathematics, solid mechanics, methods for design against uncertainty and engineering education. Address: 231 MAE-A Building, University of Florida, Gainesville, FL, USA 32611-6250; e-mail: rarosca@ufl.edu

DIANE P. HICKEY is a second year doctoral student in the Materials Science and Engineering Department at University of Florida as well as the graduate student coordinator for the UF branch of Society of Women Engineers. She holds a BS in Chemical Engineering from Auburn University. Address: 484 New Engineering Bldg., PO Box 116400, University of Florida, Gainesville, FL, 32611-6400.email: dhickey@ufl.edu 